University of Nebraska - Lincoln

DigitalCommons@University of Nebraska-Lincoln

H. W. Manter Laboratory Library Materials

9-1914

Observations on the Eggs of Ascaris lumbricoides

Winthrop D. Foster

Bureau of Animal Industry, United States Department of Agriculture

Follow this and additional works at: https://digitalcommons.unl.edu/manterlibrary

Part of the Parasitology Commons

Foster, Winthrop D., "Observations on the Eggs of Ascaris lumbricoides" (1914). H. W. Manter Laboratory Library Materials. 5.

https://digitalcommons.unl.edu/manterlibrary/5

This Article is brought to you for free and open access by DigitalCommons@University of Nebraska - Lincoln. It has been accepted for inclusion in H. W. Manter Laboratory Library Materials by an authorized administrator of DigitalCommons@University of Nebraska - Lincoln. 


\title{
OBSERVATIONS ON THE EGGS OF ASCARIS LUMBRICOIDES
}

\author{
Winthrop D. Foster
}

Junior Zoologist, Bureau of Animal Industry, U. S. Department of Agriculture.

The appearance of the ova of Ascaris lumbricoides as seen in fresh feces is so well known to physicians and zoologists that description is unnecessary. Occasionally, however, ascarid eggs are found which differ so widely from the normal egg of Ascaris lumbricoides as to cause considerable confusion on the part of observers, and may even be so misleading in appearance as to be attributed to another species. One of these atypical forms, the unfertilized egg of Ascaris lumbricoides, first reported by Miura and Nishiuchi (1902), is by no means rare, and is usually seen in the feces of persons infested with female parasites only (Fig. 1).

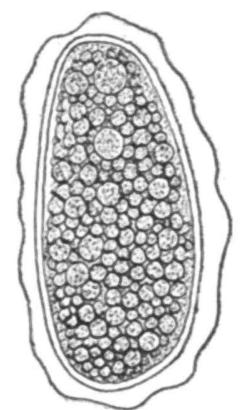

Fig. 1.-Unfertilized egg of Ascaris lumbricoides. After Miura and Nishiuchi, 1902.

Another atypical egg, differing from the normal egg only in size, has an exceptionally long major axis, while its width is no greater than that of the average egg, thus giving it a narrow elliptical form instead of the broad oval of the average egg. A sample of feces received from Florida contained numbers of eggs of this form, no eggs of average size being present. In this case the variation from the normal egg was so marked that it was only after having observed similar eggs known to have come from Ascaris lumbricoides, I could be certain of the identification. Although not reported in the literature, except for a brief note by the writer (Foster, 1913), this type of ascarid egg is apparently not rare. Drs. Stitt and Garrison, in conversation with the writer, reported seeing this atypical form in feces in Manila, while Dr. Stiles told the writer that he had seen several cases while engaged in hookworm work in the Southern states. The appearance of the 
elongated egg contrasted with the normal egg is shown in Figures 2 and 3.

As the result of the measurement of over 200 eggs, half of which were derived from dissections of ascarids from man and half from ascarids of pigs, I find that there is no sharp demarcation between the excessively long egg and the average egg, but specimens can be found making a complete series. By averaging all eggs having the same

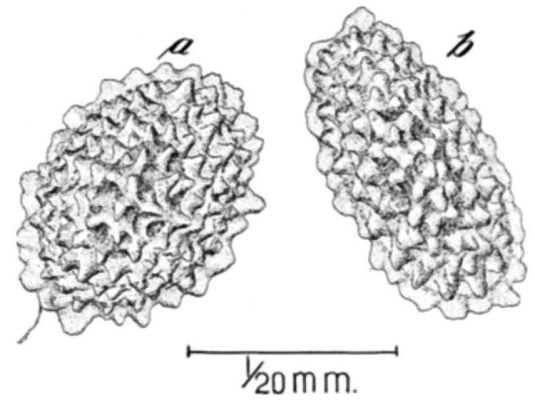

Fig. 2.--Superficial view of eggs of Ascaris lumbricoides. a, normal egg; $b$, elongated form.

length but different diameters, and arranging the results in the order of increasing length, it was found that the diameter remained fairly constant as the length of the egg increased. It follows as a corollary

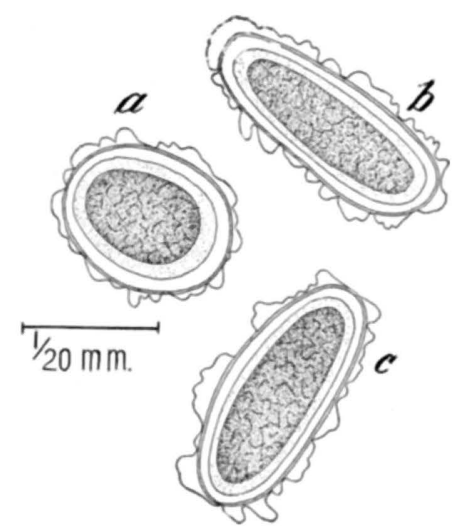

Fig. 3.-Eggs of Ascaris lumbricoides seen in optical section. a, normal egg; $b$ and $c$, elongated forms.

that as the length of the eggs of Ascaris lumbricoides increases, the ratio of the diameter to the length steadily decreases. This rule was found to apply both to those eggs derived from ascarids from swine and to those from man. There are of course many slight exceptions to this rule, but if a sufficient number of eggs are measured to serve as 
a fair basis of comparison, it will be seen that but little variation is found in the diameter of the eggs measured, while the length may vary throughout a range of 51 microns between the shortest and longest egg. When ratios are considered, instead of actual measurements, the exceptions to the corollary of the rule are very few, since individual variations are largely neutralized when expressed in terms of relative values.

The accompanying diagram (Fig. 4) shows how little variation is seen in the diameter of ascarid eggs, compared to the great variation in length. In the left-hand column, representing measurements of ascarid eggs from swine, there is a variation of 29 microns between the maximum and minimum length, although both extremes have the same diameter, which is only 7 microns less than the average diameter of all eggs measured. In the right-hand column, representing the longest and shortest egg seen in ascarids from man, there is a difference of 51 microns between the maximum and minimum lengths, while the diameter of the longest egg is actually 8 microns less than that of the shortest egg and is 12 microns less than the average diameter of all eggs measured.

The fact that all eggs, no matter what their length, have a fairly uniform diameter, would seem to be based on some morphologic structure of the female genital tract. If at some point in their development, the eggs, while still in a plastic condition, were forced lengthwise through a narrow lumen admitting only one egg at a time, we should expect to find all the eggs of a given worm having approximately the same diameter. It is evident that this modification cannot take place in the vagina, for although eggs usually pass out of the vagina in single file, dissection of the uterus shows the extremely long eggs and average eggs all having approximately the same diameter, in the proximal portion of the uterus before the eggs have passed through the vagina. Besides, the muscular wall of the vagina will expand to accommodate itself to the different diameters of the eggs rather than force them to conform to its own diameter, since the chitinous shell allows of very little if any compression. The modifying influence, if any such is present, must therefore be exerted at some point in the genital tract before the egg receives its shell, or while in the process of shell formation. As Leuckart (1867) calls attention to the fact that eggs in the posterior uterus before their shells are fully formed have approximately the same diameter though varying in length, it occurred to the writer that this modifying influence might take place as the eggs pass from the receptaculum seminis, the region immediately posterior of the uterus, into the uterus. The receptaculum seminis is separated from the uterus by a narrow sphincter-like constriction described by 


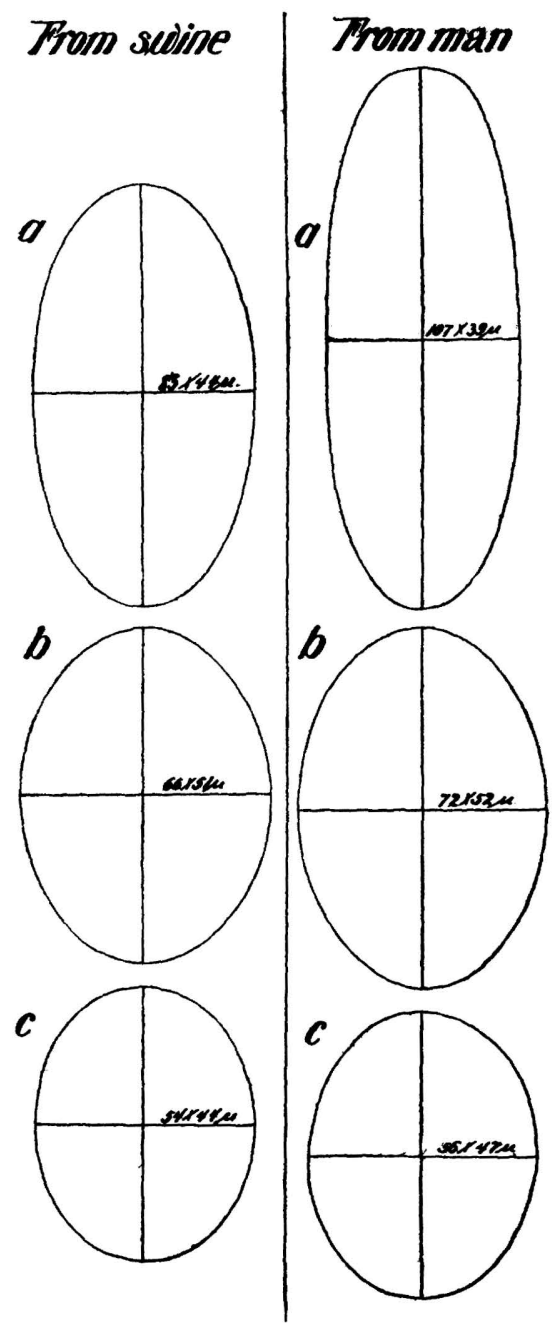

Fig. 4.-Diagram based on measurements of over 200 ascarid eggs from man and from swine, illustrating the principle that the diameter remains fairly constant as the length of the eggs increases. $a$, eggs of maximum length, from swine and from man respectively; $b$, eggs of average length; $c$, eggs of minimum length. 
Leuckart (1867) and at this point the eggs are still plastic, as they do not receive their shells (according to Blanchard, 1888) until the eggs have traversed the posterior half of the uterus. Cross-sections of this sphincter, however, show that its lumen, while considerably narrower than the preceding or subsequent parts of the genital tract, is sufficiently large to allow many eggs to pass through at one time. The writer has examined cross-sections of the entire posterior half of the uterus without finding any place where the eggs when in a plastic condition would be subjected to pressure tending to give them a uniform diameter.

While the uniform diameter of eggs from the same worm may be explained by some such morphologic modification as suggested above, it is harder to explain the fact that eggs from different worms varying greatly in size, have approximately the same diameter. It is hardly reasonable to assume that the lumen of the genital tract in different worms would have approximately the same diameter at the same place, for since the external measurements of different adult individuals is subject to great variation, we should expect and in fact do find, corresponding variations in the measurements of the internal organs.

Table of measurements of eggs of Ascaris lumbricoides from man and from swine, arranged in order of decreasing length, to show that as the length decreases, the width remains constant or slightly increases. Measurements in microns. Each set of measurements represents the averages of five individual eggs from the same worm. In those cases where the measurements have the same length but different widths, the corresponding ratio is the ratio of the average width to the given length.

\begin{tabular}{|c|c|c|c|c|c|c|c|c|}
\hline TABLE & 1.-FRON & SWINE & \multicolumn{3}{|c|}{ TABLE 2.-FROM MAN } & \multicolumn{3}{|c|}{$\begin{array}{c}\text { TABLE 3.-COMBINED FROM } \\
\text { ONE AND TWO }\end{array}$} \\
\hline Length & Width & Ratio & Length & Width & Ratio & Length & Width & Ratio \\
\hline $\begin{array}{l}73.0 \\
73.0 \\
70.5 \\
70.5 \\
68.0 \\
68.0 \\
68.0 \\
66.0 \\
65.5 \\
65.5 \\
65.5 \\
64.5 \\
63.5 \\
63.5 \\
62.5 \\
62.0 \\
61.0 \\
56.5\end{array}$ & $\left.\begin{array}{l}56.5 \\
49.0 \\
51.5 \\
49.0 \\
56.5 \\
54.0 \\
56.5\end{array}\right\}$ & $\begin{array}{l}72.1 \\
71.3 \\
81.3 \\
76.5 \\
\\
81.0 \\
69.7 \\
72.6 \\
84.0 \\
79.0 \\
77.8 \\
82.3\end{array}$ & $\begin{array}{l}87.5 \\
78.0 \\
78.0 \\
78.0 \\
75.5 \\
73.0 \\
73.0 \\
71.5 \\
71.0 \\
70.5 \\
69.0 \\
68.0 \\
68.0 \\
65.5 \\
65.0 \\
64.5 \\
63.5 \\
63.5 \\
62.0\end{array}$ & $\left.\begin{array}{l}49.0 \\
46.5 \\
51.5 \\
50.5 \\
57.5 \\
56.5 \\
54.0 \\
55.5 \\
51.5 \\
51.5 \\
49.0 \\
51.5 \\
49.0 \\
48.5 \\
54.0 \\
52.5 \\
59.5 \\
46.5 \\
53.0\end{array}\right\}$ & $\begin{array}{l}56.0 \\
63.5 \\
76.2 \\
75.3 \\
77.6 \\
72.5 \\
73.0 \\
71.0 \\
73.4 \\
74.0 \\
83.0 \\
81.3 \\
73.2 \\
85.4\end{array}$ & $\begin{array}{l}87.5 \\
78.0 \\
75.5 \\
73.0 \\
71.5 \\
71.0 \\
70.5 \\
69.0 \\
68.0 \\
66.0 \\
65.5 \\
65.0 \\
64.5 \\
63.5 \\
62.0 \\
61.0 \\
56.5\end{array}$ & $\begin{array}{l}49.0 \\
49.5 \\
57.5 \\
54.0 \\
55.5 \\
51.5 \\
51.0 \\
49.0 \\
53.0 \\
50.5 \\
51.0 \\
54.0 \\
49.0 \\
49.5 \\
51.0 \\
47.5 \\
46.5\end{array}$ & $\begin{array}{l}56.0 \\
63.5 \\
76.2 \\
74.0 \\
77.6 \\
72.5 \\
72.3 \\
71.0 \\
77.9 \\
76.5 \\
77.9 \\
83.1 \\
76.0 \\
78.0 \\
82.3 \\
77.9 \\
82.3\end{array}$ \\
\hline
\end{tabular}


REFERENCES CITED

Blanchard, R. 1888. Traité de zoologie médicale. 1: 481-808.

Foster, W. D. 1913. Some Atypical Forms of the Eggs of Ascaris lumbricoides. Science, n. s. 37: 78.

Leuckart, R. 1867. Die menschlichen Parasiten und die von ihnen herrührenden Krankheiten, v. 2, 1. Lief.

Miura, K., and Nishiuchi, N. 1902. Ueber befruchtete und unbefruchtete Ascarideier im menschlichen Kote. Centralbl. f. Bakt., Abt., Orig., 32: 637-641. 